\title{
Acceleration Amplifications in NIF Structures Subjected to Earthquake Base Motions
}

\author{
D. McCallen
}

November 29, 1999

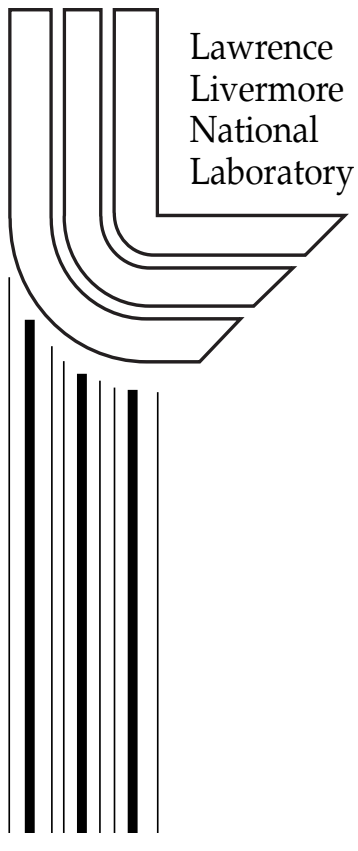




\section{DISCLAIMER}

This document was prepared as an account of work sponsored by an agency of the United States Government. Neither the United States Government nor the University of California nor any of their employees, makes any warranty, express or implied, or assumes any legal liability or responsibility for the accuracy, completeness, or usefulness of any information, apparatus, product, or process disclosed, or represents that its use would not infringe privately owned rights. Reference herein to any specific commercial product, process, or service by trade name, trademark, manufacturer, or otherwise, does not necessarily constitute or imply its endorsement, recommendation, or favoring by the United States Government or the University of California. The views and opinions of authors expressed herein do not necessarily state or reflect those of the United States Government or the University of California, and shall not be used for advertising or product endorsement purposes.

This work was performed under the auspices of the U.S. Department of Energy by the University of California, Lawrence Livermore National Laboratory under Contract No. W-7405-Eng-48.

This report has been reproduced directly from the best available copy.

Available electronically at http://www.doe.gov/bridge

Available for a processing fee to U.S. Department of Energy

and its contractors in paper from

U.S. Department of Energy

Office of Scientific and Technical Information

$$
\text { P.O. Box } 62
$$

Oak Ridge, TN 37831-0062

Telephone: (865) 576-8401

Facsimile: (865) 576-5728

E-mail: reports@adonis.osti.gov

Available for the sale to the public from

U.S. Department of Commerce

National Technical Information Service

5285 Port Royal Road

Springfield, VA 22161

Telephone: (800) 553-6847

Facsimile: (703) 605-6900

E-mail: orders@ntis.fedworld.gov

Online ordering: http://www.ntis.gov/ordering.htm

OR

Lawrence Livermore National Laboratory

Technical Information Department's Digital Library

http://www.llnl.gov/tid/Library.html 


\title{
Acceleration Amplifications in NIF Structures Subjected to Earthquake Base Motions
}

\author{
D. McCallen \\ Center for Complex Distributed Systems
}

\subsection{Background}

NIF technical staff have questioned the possibility of obtaining acceleration amplifications (i.e. amplification of the ground acceleration values) in a structure which are significantly higher than the acceleration amplification exhibited across the period range in the input response spectrum. This note utilizes a simple example to illustrate that the acceleration amplification resulting from the dynamic response of a structural system can indeed be significantly higher than the amplifications indicated in the response spectrum, and that the GEMINI program is computing the appropriate acceleration levels for a simple MDOF system.

\subsection{Equations of motion for MDOF and SDOF systems}

\section{$M D O F$}

The governing coupled ODE's describing the motion of a MDOF system subjected to base motion are given by,

$$
[M]\left\{\ddot{x}_{r}\right\}+[C]\left\{\dot{x}_{r}\right\}+[K]\left\{x_{r}\right\}=-[M]\{1\} \ddot{x}_{g}(t)
$$

Where $\ddot{x}_{g}(t)$ is the time variant acceleration of the ground and the subscript " $r$ " denotes relative displacement quantities (i.e. displacement of the structure relative to the ground). Equation 1 also assumes that all degrees of freedom must subtract the ground displacement in order to develop the relative displacement term, hence the unity vector on the right hand side. Classical modal analysis of this equation is developed by writing the relative displacements of the structure as a linear combination of the natural free vibration modeshapes of the system,

$$
\begin{aligned}
& \left\{x_{r}(t)\right\}=[A]\{\Psi(t)\} \\
& \left\{\dot{x}_{r}(t)\right\}=[A]\{\Psi(t)\} \\
& \left\{\ddot{x}_{r}(t)\right\}=[A]\{\Psi \ddot{(}(t)\}
\end{aligned}
$$


Where $[A]$ is the matrix containing the natural modeshapes of the structural system and $\{\Psi(t)\}$ is the vector of "normal coordinates" which define the amplitude of each modal contribution. Substituting EQ 2 through EQ 4 into EQ 1 yields,

$$
[M][A]\{\ddot{\Psi}\}+[C][A]\{\dot{\Psi}\}+[K][A]\{\Psi\}=[M]\{1\} \ddot{x}_{g}(t)
$$

In EQ 5 the time argument has been dropped for simplicity, the time variant nature of the response is implicitly assumed. In addition, the negative sign on the right hand side has been dropped for simplicity sake. Premultiplying EQ 5 by the transpose of the modal vector yields

$$
[A]^{T}[M][A]\{\ddot{\Psi}\}+[A]^{T}[C][A]\{\dot{\Psi}\}+[A]^{T}[K][A]\{\Psi\}=[A]^{T}[M]\{1\} \ddot{x}_{g}(t)(\mathrm{EQ} 6)
$$

\section{Orthogonality of the natural modeshapes}

Significant simplification of EQ 6 can be obtained by exploiting the orthogonality condition of the natural modeshapes. The free vibration eigenproblem is given by

$$
[K]\left\{A_{i}\right\}-\omega_{i}^{2}[M]\left\{A_{i}\right\}=\{0\}
$$

Where $\left\{A_{i}\right\}$ is the ith natural modeshape and $\omega_{i}$ is the ith natural frequency in $\mathrm{rad} / \mathrm{sec}$.

Premultiplication of EQ 7 by another mode $\left\{A_{j}\right\}^{T}$ yields,

$$
\left\{A_{j}\right\}^{T}[K]\left\{A_{i}\right\}=\omega_{i}^{2}\left\{A_{j}\right\}^{T}[M]\left\{A_{i}\right\}
$$

For the second natural mode $\left\{A_{j}\right\}$ the eigenproblem can be written

$$
[K]\left\{A_{j}\right\}=\omega_{j}^{2}[M]\left\{A_{j}\right\}
$$

Taking the transpose of both sides of EQ 9 and post multiplying by $\left\{A_{i}\right\}$ gives

$$
\left\{A_{j}\right\}^{T}[K]\left\{A_{i}\right\}=\omega_{j}^{2}\left\{A_{j}\right\}^{T}[M]\left\{A_{i}\right\}
$$

Subtracting EQ 10 from EQ 8 yields,

$$
\{0\}=\left(\omega_{i}^{2}-\omega_{j}^{2}\right)\left\{A_{j}\right\}^{T}[M]\left\{A_{i}\right\}
$$

Which can only be true if

$$
\left\{A_{j}\right\}^{T}[M]\left\{A_{i}\right\}=0
$$

Combining EQ 12 and EQ 8 then yields 


$$
\left\{A_{j}\right\}^{T}[K]\left\{A_{i}\right\}=0
$$

Equation 13 and EQ 12 provide the orthogonality relationships central to modal analysis techniques. Invoking EQ 12 and EQ 13 in EQ 6 yields,

$$
\left[M^{*}\right]\{\ddot{\Psi}\}+\left[C^{*}\right]\{\dot{\Psi}\}+\left[K^{*}\right]\{\Psi\}=\{L\} \ddot{x}_{g}(t)
$$

Where, as a result of the orthogonality conditions in EQ 12 and EQ 13, $\left[M^{*}\right]$ and [ $\left.K^{*}\right]$ are diagonal matrices with the diagonal terms given by

$$
\begin{aligned}
m_{i i} & =\left\{A_{i}\right\}^{T}[M]\left\{A_{i}\right\} \\
k_{i i} & =\left\{A_{i}\right\}^{T}[K]\left\{A_{i}\right\}
\end{aligned}
$$

It is assumed that the modeshapes are also orthogonal to the damping matrix, and that $\left[C^{*}\right]$ is given by

$$
c_{i i}=2 \beta \omega_{i} m_{i i}
$$

and $\{L\}$ is given by

$$
L_{i}=\sum_{k=1}^{N D O F} m_{k} A_{k_{i}}
$$

and in EQ 18, $m_{k}$ is the mass lumped at DOF "k" and $A_{k_{i}}$ is the component at DOF "k" of the "ith" mode.

Equation 14 provides a set of decoupled equations in normal coordinate space, the "ith" modal equation is given by

$$
m_{i i} \ddot{\Psi}_{i}+2 \beta \omega_{i} m_{i i} \dot{\Psi}_{i}+k_{i i} \Psi_{i}=L_{i} \ddot{x}_{g}(t)
$$

\section{$S D O F$}

The equation of motion of a single degree of freedom system subjected to base acceleration is given by

$$
m \ddot{x}_{r}+2 \beta \omega m \dot{x}_{r}+k x_{r}=m \ddot{x}_{g}(t)
$$

The response spectrum ordinates provide a plot of the maximum values obtained from this equation as a function of system frequency (or period). Thus the spectral ordinates essentially provide a solution of the linear equation given in EQ. 20. The spectral types of importance here are the relative displacement spectrum and the absolute acceleration spec- 
trum (Fig. 1). The "ith" modal equation (EQ 19) and the SDOF equation of motion (EQ

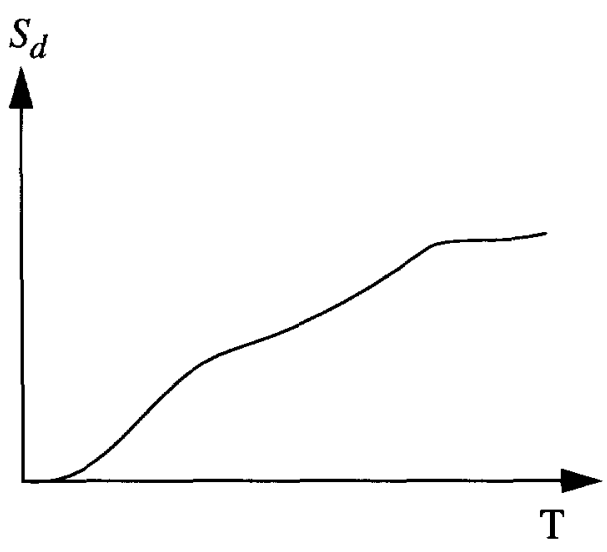

a)

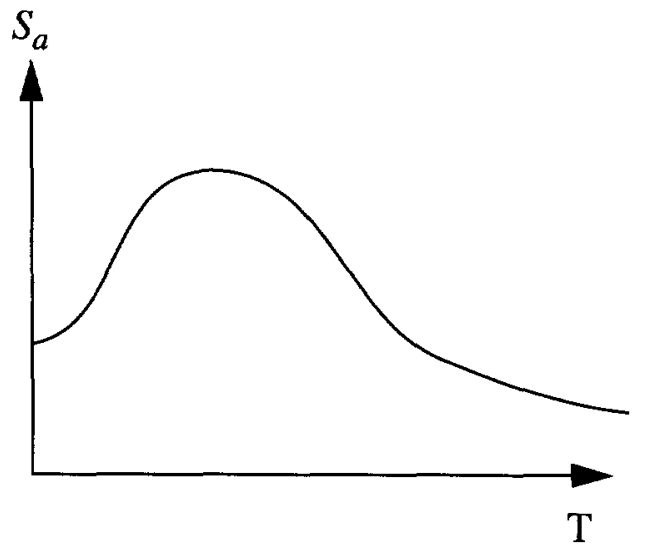

b)

FIGURE 1. Response spectrum. a) relative displacement spectrum; b) absolute acceleration spectrum

20) can be rewritten

$$
\begin{gathered}
\ddot{\Psi}_{i}+2 \beta \omega_{i} \dot{\Psi}_{i}+\omega_{i}^{2} \Psi_{i}=\frac{L_{i}}{m_{i i}} \ddot{x}_{g}(t) \\
\ddot{x}_{r}+2 \beta \omega \dot{x}_{r}+\omega^{2} x_{r}=\ddot{x}_{g}(t)
\end{gathered}
$$

Comparing EQ 21 and EQ 22, and relying on the linearity of the equations, the maximum normal mode coordinate can be obtained from the spectral displacement ordinate via simple linear scaling,

$$
\Psi_{i_{\max }}=\frac{L_{i}}{m_{i i}} S_{d}
$$

To express the maximum normal mode coordinate in terms of spectral acceleration requires the utilization of the fact that in the SDOF system, the peak inertial force and the peak elastic forces occur at nearly the same instant in time (i.e. when the peak relative displacement occurs the accelerations are also a maximum) and the peak elastic and inertial forces are nearly equal (the velocity is approximately zero at the peak response and thus the damping forces are approximately zero). For the SDOF freedom system this can be expressed as

$$
F_{\text {elastic }_{\max }}=F_{\text {inertial }_{\max }}
$$

or

$$
m S_{a}=k S_{d}
$$


thus

$$
S_{d} \approx \frac{S_{a}}{\omega^{2}}
$$

Combining EQ 26 and EQ 23 yields,

$$
\Psi_{i_{\max }}=\frac{L_{i}}{m_{i i} \omega_{i}{ }^{2}}
$$

The maximum normal coordinate is thus

$$
\Psi_{i_{\max }}=\frac{\sum_{k=1}^{N D O F}\left(m_{k} A_{k_{i}}\right)}{\sum_{k=1}^{N D O F}\left(m_{k} A_{k_{i}}^{2}\right)}\left(\frac{S_{a}}{\omega_{i}^{2}}\right)
$$

Similarly to the SDOF system, for a MDOF structure vibrating in the "ith" mode, the maximum inertial forces are approximately equal to the maximum elastic forces thus,

$$
[M]\{\ddot{x}\}_{\max }=[K]\left\{A_{i}\right\} \Psi_{i_{\max }}
$$

Combining EQ 29 and EQ 28 yields

$$
\{\ddot{x}\}_{\max }=[M]^{-1}[K]\left\{A_{i}\right\}\left(\frac{\sum_{k=1}^{N D O F}\left(m_{k} A_{k_{i}}\right)}{\sum_{k=1}^{N D O F}\left(m_{k} A_{k_{i}}^{2}\right)}\left(\frac{S_{a}}{\omega_{i}^{2}}\right)\right)
$$

From the MDOF eigenproblem (EQ 7),

$$
\begin{gathered}
{[M]^{-1}[K]\left\{A_{i}\right\}=\omega_{i}^{2}\left\{A_{i}\right\}} \\
\{\ddot{x}\}_{\text {max }}=\left\{A_{i}\right\}\left(\begin{array}{l}
\sum_{k=1}^{N D O F}\left(m_{k} A_{k_{i}}\right) \\
\sum_{k=1}^{N D O F}\left(m_{k} A_{k_{i}}^{2}\right)
\end{array}\right)
\end{gathered}
$$




\subsection{Example problems}

To evaluate the potential acceleration amplification in a simple system, the two degree of freedom mass system shown in Fig. 2 is considered.

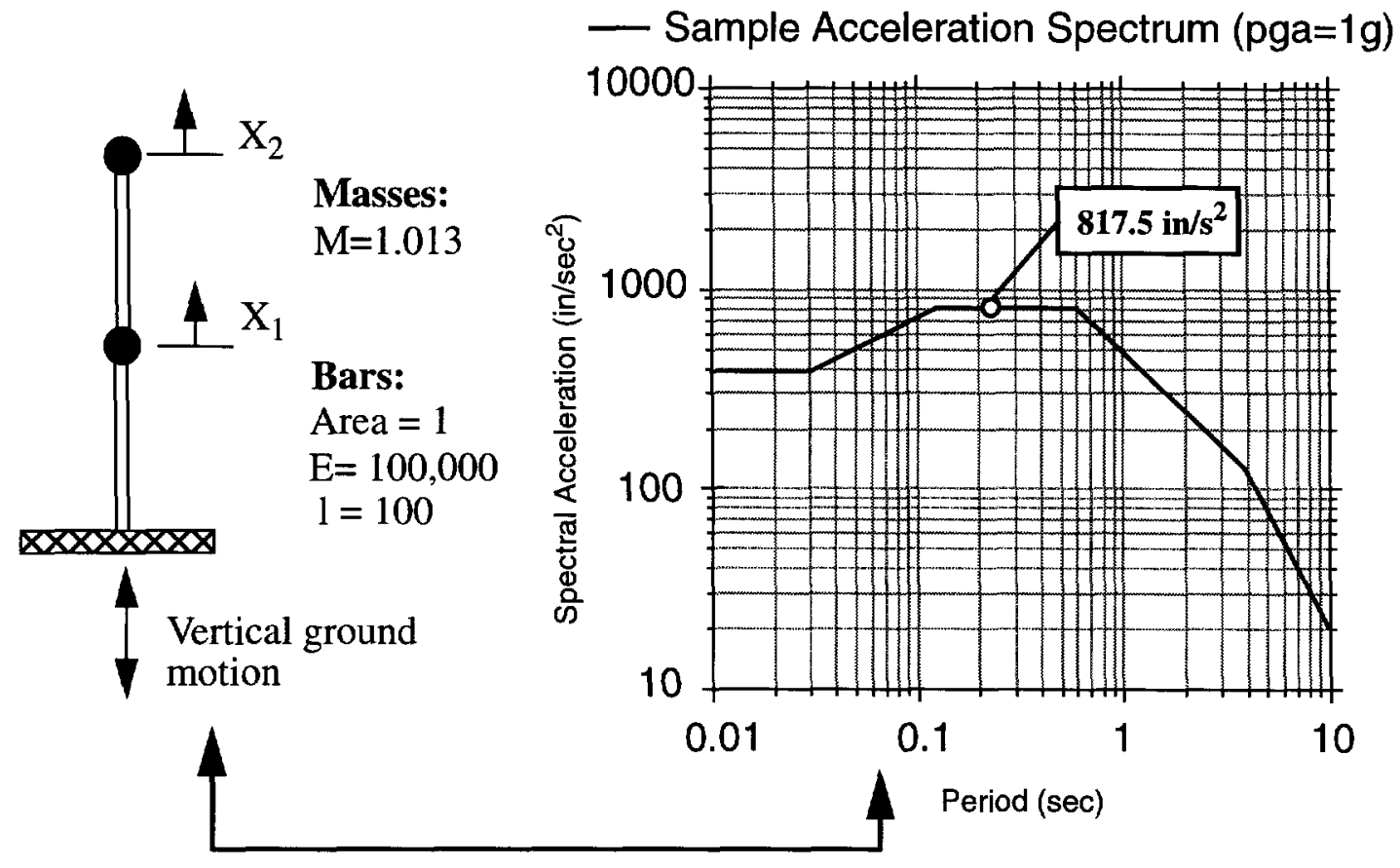

FIGURE 2. Sample two degree of freedom problem

The eigenproblem for this simple structure is given by,

$$
\omega^{2}[M]\{A\}=[K]\{A\}
$$

or

$$
\left[[K]-\omega^{2}[M]\right]\{A\}=\{0\}
$$

The homogeneous system of equations given in EQ 34 can have a solution only if the coefficient matrix is rank deficient, i.e.

$$
\operatorname{det}\left[[K]-\omega^{2}[M]\right]=0
$$

Writing EQ 34 in terms of the problem parameters yields,

$$
\left[\left[\begin{array}{cc}
2000 & -1000 \\
-1000 & 1000
\end{array}\right]-\omega^{2}\left[\begin{array}{cc}
1.013 & 0 \\
0 & 1.013
\end{array}\right]\right]\left[\begin{array}{l}
A_{1} \\
A_{2}
\end{array}\right]
$$

and the determinantal equation becomes, 


$$
1.026\left(\omega^{2}\right)^{2}-3039\left(\omega^{2}\right)+1 \times 10^{6}
$$

Solving this quadratic equation for $\omega^{2}$ yields $\omega_{1}=50.78 \mathrm{rad} / \mathrm{sec}$ and $\omega_{2}=19.58 \mathrm{rad} /$ sec. Back-substituting the eigenvalues into EQ 36 yields the eigenvectors and the results are summarized in Fig. 3.

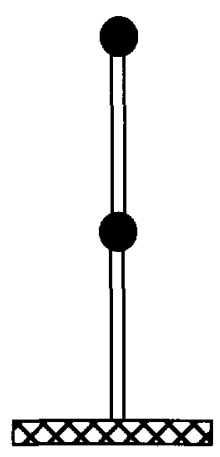

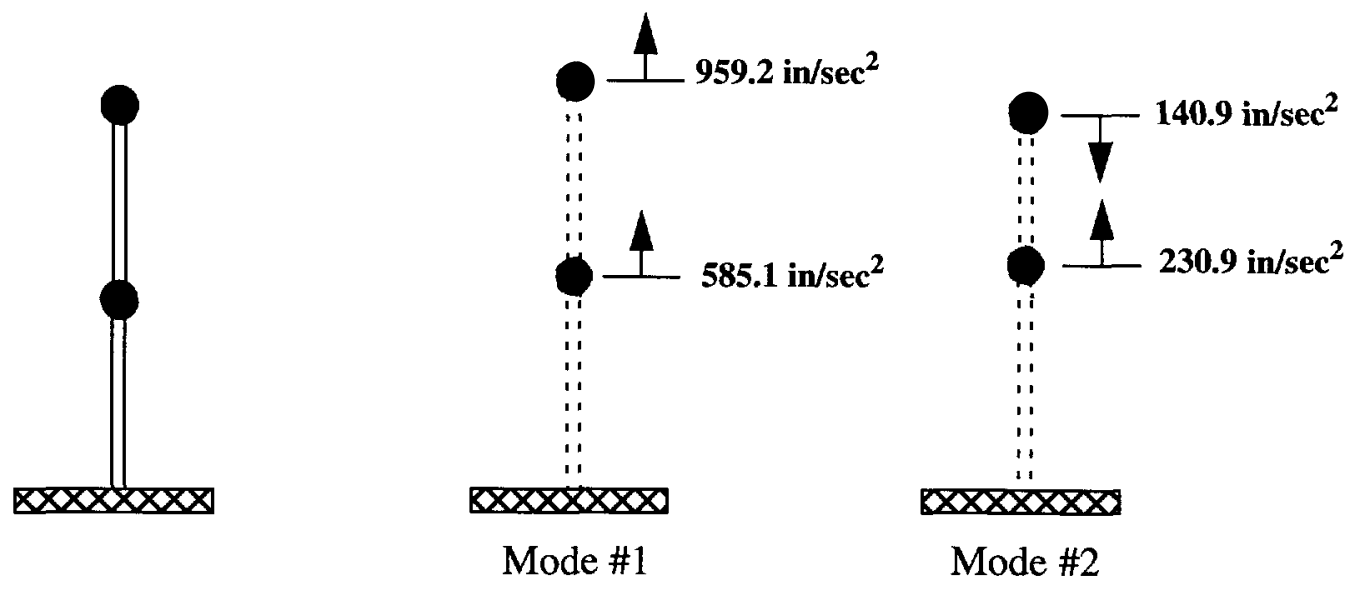

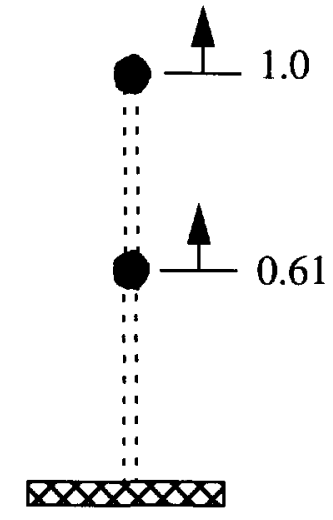

Mode \#1

$\mathrm{F}=3.11 \mathrm{~Hz}$

$(\mathrm{T}=0.322 \mathrm{sec})$

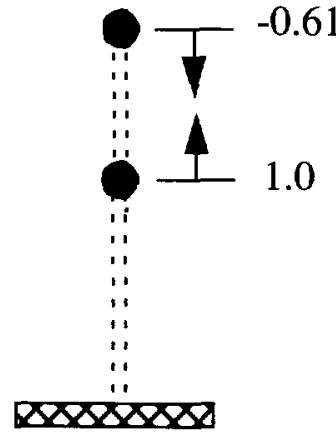

Mode \#2

$$
\mathrm{F}=8.08 \mathrm{~Hz}
$$

$(\mathrm{T}=0.124 \mathrm{sec})$

FIGURE 3. Analytical modeshapes and frequencies of the 2 DOF system

The peak accelerations due to each mode are given by EQ 32, and the modal accelerations are summarized in Fig. 4. Performing an SRSS modal combination, the response spectrum

FIGURE 4. Peak modal accelerations for the 2 DOF system

acceleration estimates are given in Fig. 5. For comparison the acceleration values obtained from a GEMINI computer model of this system are also shown in Fig. 5. The analytical and GEMINI solution are in very good agreement. Comparing Fig. 5 and Fig. 2, it is clear that a MDOF dynamical system can have acceleration values in exceedance of the peak spectral values. 


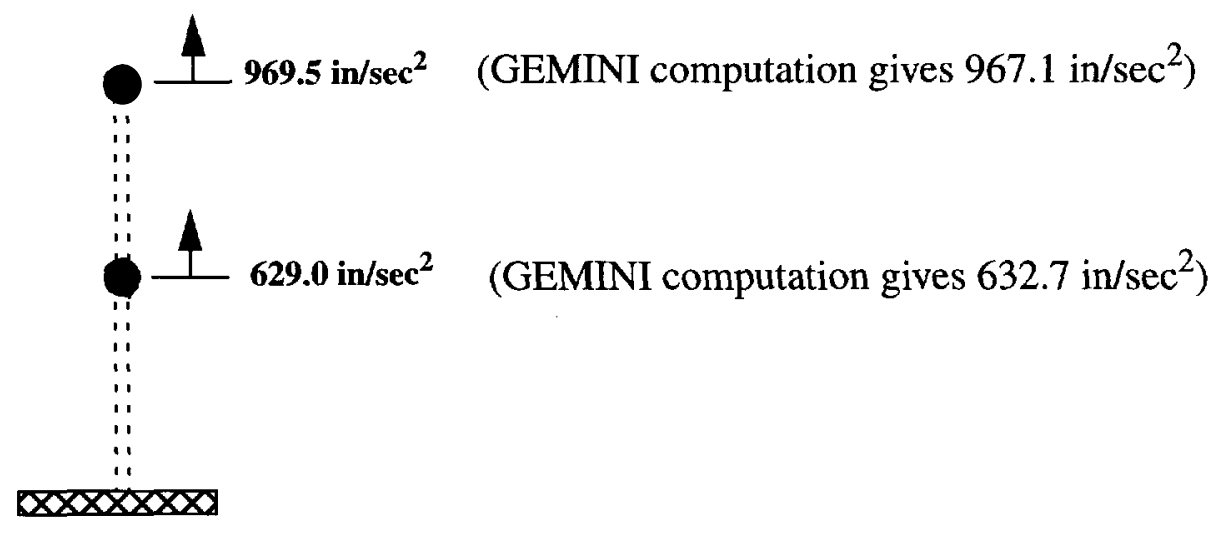

FIGURE 5. System accelerations obtained from analytical and GEMINI solutions

The simple example given above validates the GEMINI solutions numbers and illustrates the ability to get structural accelerations over and above the spectral amplitudes in a MDOF system. The simple example shown had a uniform stiffness and mass distribution. Significantly more dramatic acceleration amplifications can be observed for a system with nonuniform stiffness and mass distribution. Consider the nonuniform system shown in Fig. 6.

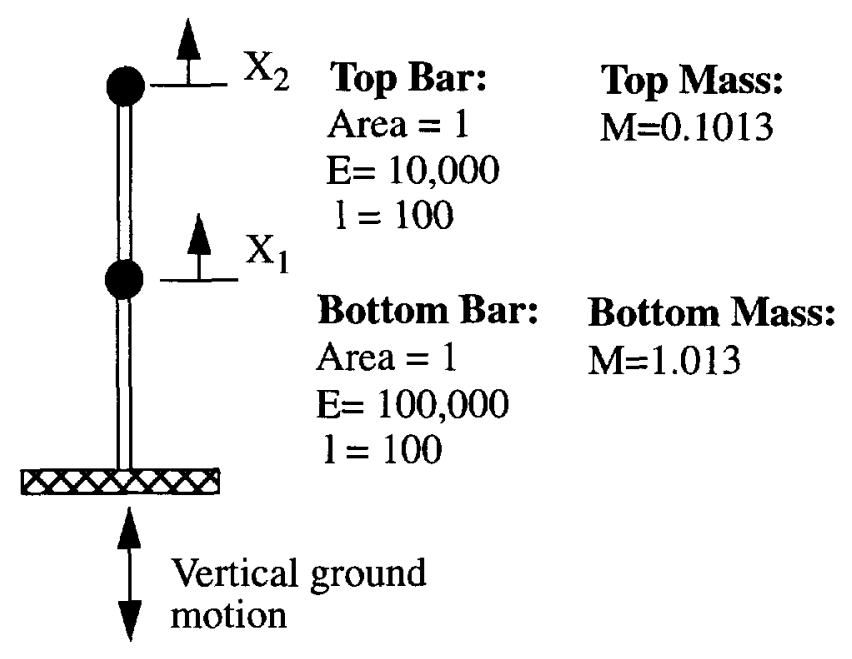

FIGURE 6. Nonuniform two degree of freedom system

The natural modeshapes and associated frequencies of this system computed with the expressions derived above are shown in Fig. 7. The computed modal contributions to the accelerations are shown in Fig. 8 and the SRSS modal combination of the accelerations are shown in Fig. 9.

Two things are evident from the plots in Fig. 7 to Fig. 9 and Fig. 2, first the analytically derived solution agrees quite well with the GEMINI solution, secondly the in-structure accelerations dramatically exceed the spectral accelerations $(1982>817)$ by a factor of 2.4 . 

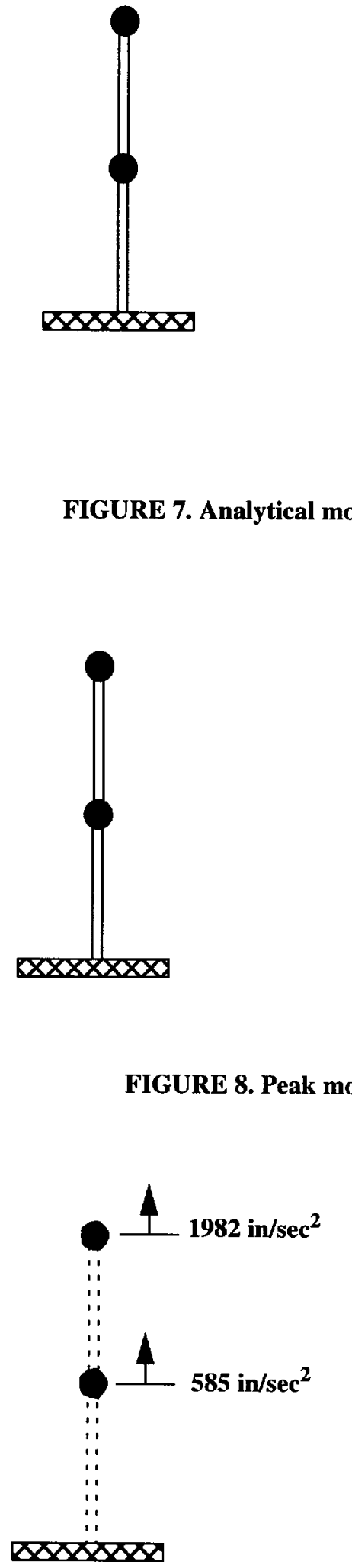

(GEMINI computation gives $585 \mathrm{in} / \mathrm{sec}^{2}$ )

FIGURE 9. System accelerations obtained from analytical and GEMINI solutions 
These acceleration amplification levels can be understood when it is recognized that for this second system the top portion is significantly less massive than the bottom and significantly more flexible. This results in the bottom portion acting essentially like a SDOF system which amplifies the ground motion, which in turn provides input to the smaller second system above. The second system then reamplifies the already amplified motion to get the very large accelerations at the top. This effect is shown schematically in Fig. 10.

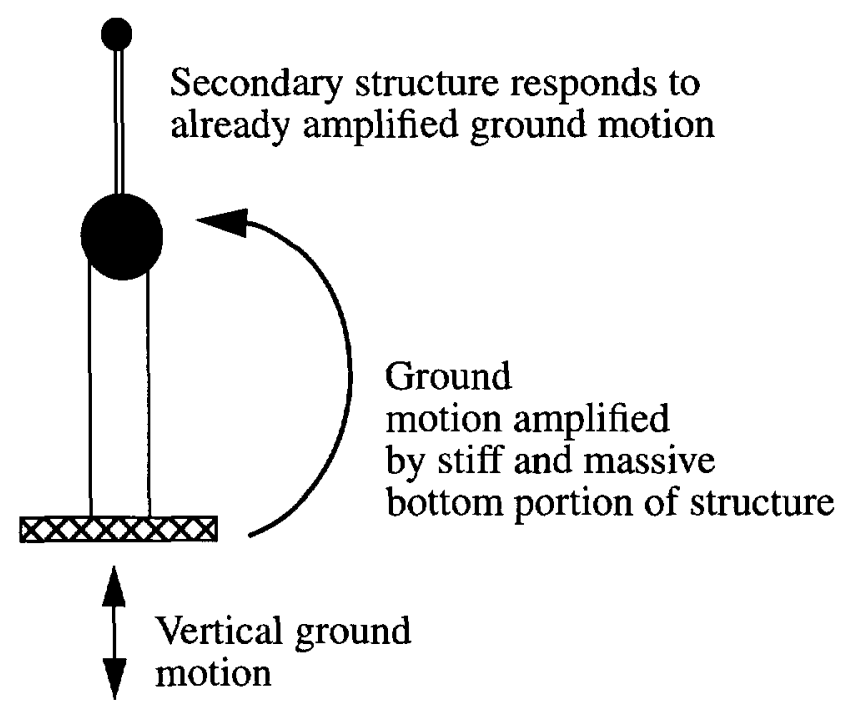

FIGURE 10. Physics of system which attains large structural accelerations

Acknowledgement- This work was performed at the Lawrence Livermore National Laboratory under the auspices of the United States Department of Energy, contract no. W-7405Eng-48. 